BULLETIN Bulletin hispanique

HISPANIQUE Université Michel de Montaigne Bordeaux

117-2 | 2015

Métamorphose(s) : représentations et réécritures

\title{
Rafael Alarcón Sierra, «Vértice de llama». El Greco en la literatura hispánica. Estudio y antología poética
}

Universidad de Valladolid, Valladolid, 2014

\section{Marta Palenque}

\section{(2) OpenEdition}

\section{Journals}

Edición electrónica

URL: http://journals.openedition.org/bulletinhispanique/4155

DOI: 10.4000/bulletinhispanique.4155

ISSN: $1775-3821$

\section{Editor}

Presses universitaires de Bordeaux

Edición impresa

Fecha de publicación: 15 diciembre 2015

Paginación: 762-765

ISBN: 979-10-300-0041-2

ISSN: 0007-4640

Referencia electrónica

Marta Palenque, «Rafael Alarcón Sierra, «Vértice de llama». El Greco en la literatura hispánica. Estudio y antología poética », Bulletin hispanique [En línea], 117-2 | 2015, Publicado el 15 diciembre 2015, consultado el 22 septiembre 2020. URL : http://journals.openedition.org/bulletinhispanique/4155 ; DOI : https://doi.org/10.4000/bulletinhispanique.4155

Este documento fue generado automáticamente el 22 septiembre 2020.

Tous droits réservés 


\title{
Rafael Alarcón Sierra, «Vértice de Ilama». El Greco en la literatura hispánica. Estudio y antología poética
}

Universidad de Valladolid, Valladolid, 2014

\author{
Marta Palenque
}

\section{REFERENCIA}

Rafael Alarcón Sierra, «Vértice de llama». El Greco en la literatura hispánica. Estudio y antología poética. Valladolid, Universidad de Valladolid, 2014, 316 p. ISBN:

978-84-8448-816-3.

1 «Aquí, el barro ascendiendo a vértice de llama»: este es el verso inicial del poema que Rafael Alberti dedicó a El Greco en su hermoso A la pintura. Cantata de la línea y el color (1945) y que el autor de este ensayo, el profesor de la Universidad de Jaén Rafael Alarcón Sierra, utiliza para iluminar, desde el título, esta suerte de viaje museográfico y literario por la obra y biografía del pintor.

2 El centenario de El Greco, celebrado en el año 2014, sirve de marco para este excelente ensayo y antología. El Greco, afirma Alarcón Sierra en la introducción, «es nuestro contemporáneo» $\mathrm{y}$, ciertamente, esta idea queda refrendada por el cada vez mayor aprecio que su pintura ha alcanzado en la medida en que nos acercamos a la modernidad, que le entendió faro y guía de la vanguardia y de la ruptura con el academicismo. El ensayo se articula en dos capítulos complementarios y una antología poética final. En el primero («La construcción del Greco en la modernidad») Alarcón Sierra explica los cambios de juicio desde su época, cuando algunos le compararon con Góngora por su originalidad absoluta, pasando pronto a ser negado o infravalorado por lo que luego se calificó como extravagancia. El siglo XIX redescubrió al pintor y los románticos le alzaron como adalid de la genialidad y la libertad creadora. En esta centuria se convierte además en un artista admirado fuera de España gracias a las 
galerías y museos que, en distintos países europeos, muestran sus lienzos. También a partir de la experiencia y la narración posterior de los viajeros que visitaron nuestro país. En palabras de Alarcón Sierra, la idea del Greco «como precursor de una escuela española e intérprete del espíritu castellano y del misticismo español parece deudora de la crítica francesa» (p. 15), y es en Francia donde comienza a ser un pintor de culto. En el fin de siglo, los españoles -pintores, escritores, críticos- van a tomar al Greco para «redefinir la modernidad artística y las señas de identidad nacionales» (p. 17); Santiago Rusiñol, Ramón Casas, Ignacio Zuloaga o Darío de Regoyos le consideraron un simbolista.

3 Alarcón Sierra ha publicado muchos ensayos en torno a la literatura del Modernismo hispánico y, en concreto, varios estudios y ediciones sobre Manuel Machado, el autor de Apolo. Teatro pictórico. Me refiero principalmente a sus libros titulados Entre el modernismo y la modernidad: la poesía de Manuel Machado. Alma y Caprichos (1999) y «El mal poema» de Manuel Machado: Una lírica moderna y dialógica (2008), así como a sus ediciones manuelmachadianas: Impresiones. El modernismo. Artículos, crónicas y reseñas, 1899-1999 (2000) y Alma. Caprichos. El Mal Poema (2000). En estos ensayos Alarcón ha profundizado en las fuentes de la estética modernista, uno de cuyos rasgos principales es el sincretismo artístico. No extraña, así, que aborde ahora sin dejar fisuras la sección cronológica correspondiente a esta época, pormenorizando en autores e influencias. Se advierte que este es un volumen de redacción rigurosa y detenida, de búsqueda minuciosa de información y de referencias artísticas, menciones o alusiones a la pintura o la biografía del Greco en libros y revistas. No pesa sin embargo esta erudición en la lectura, que avanza con comodidad, desgranando las vicisitudes de la recepción del cretense, y quedan las referencias -muy ricas e inspiradoras- y citas complementarias en las notas al pie. Son importantes en este primer capítulo el comentario y análisis de aquellos escritores (Pérez Galdós, Pardo Bazán, Baroja, Azorín ...; Giner de los Ríos, Manuel Bartolomé Cossío, Aureliano de Beruete...; Ortega, d'Ors, Dalí, Ramón, Marañón) que recurren o citan al pintor en su obra narrativa, dramática o ensayística (además de los ámbitos pictórico, cinematográfico, publicitario o musical), y difunden la visión del nuevo Greco, y que, por tanto, no van a pasar a los capítulos siguientes, ya centrados en la poesía.

El segundo capítulo se ocupa de «El Greco en la poesía hispánica»-aunque Alarcón no olvida a autores como Rilke, William Carlos Williams o Bukowski- y glosa, en el comentario de los poemas dedicados a El Greco desde el siglo XVII hasta la actualidad, el cambio de gusto y de valoración expuesto de manera general en el precedente. Señala en nota Alarcón Sierra algunos libros y artículos anteriores en los que se ha realizado una selección similar, aunque ninguno con los contenidos y la extensión de lo que se ofrece aquí. Si de estudiar o conocer se trata, este capítulo puede leerse en paralelo con la antología poética, última parte del volumen, pues se valoran cada uno de los poemas e, incluso, se estiman otros que no se han recogido en el florilegio. Para gozar del placer del texto (aunque el estudio nunca estuvo reñido con él) se puede proceder por partes.

El Greco en la poesía es tanto el hombre y su biografía, como el pintor y su obra, y se le canta desde distintos puntos de vista, con resultados diferentes. Entramos en el estudio de la écfrasis, es decir, de la representación o traducción de «una forma visual, plástica, espacial, de percepción simultánea, en una forma verbal, escrita, temporal, de lectura 
sucesiva» (p. 80), y es sugerente contemplar a través de los ojos de tantos poetas que, mirando el mismo lienzo o igual técnica, percibieron mundos tan dispares.

En los primeros poemas que refiere Alarcón Sierra -de Paravicino, Góngora, C. de Mesa y J. Delitala- el Greco no es el hombre de su tiempo, sino el artista singular al que se loa o distingue como demiurgo, como a un ser especial. El siglo XVIII (representado por F. Gregorio de Salas) le hace, por el contrario, objeto de sátira y burla. Extraña su ausencia en los versos del XIX. «La paleta» de Salvador Rueda inaugura, en 1895, la transición al Modernismo (Alarcón Sierra prefiere hablar de «poesía postromántica y premodernista», p.79). El Greco aparece solo nombrado entre grandes pintores (Murillo, Velázquez, Miguel Ángel, Fortuny, Rosales) y distinguido como «enigmático». Esta composición no se copia en la antología. Juan Ramón Jiménez utilizó el término «colorismo» para referirse a la novedad que traían los versos de Rueda y, ciertamente, aunque este término tienda a minusvalorar el alcance de sus novedades, los versos del malagueño son poesía de los sentidos y todas las artes sirven como camino para expresarlo. El parnasianismo de Antonio de Zayas o Manuel Machado marca un punto de inflexión con la cifra de "retratos pictóricos», casi un subgénero poético en sí mismo, como subraya Alarcón.

El broche final de «Vértice de llama». El Greco en la literatura hispánica es la antología sobre «El Greco en la poesía hispánica», una particular galería donde imágenes, símbolos, metáforas, símiles... traducen los colores y el dibujo. Los cambios de gusto y la evolución de la estética se perciben en la selección de lienzos o en la mirada individual -deudora de su tiempo- de los poetas. Esta antología cubre un arco temporal comprendido entre 1618, fecha del volumen del que se toma el primer texto: «Al griego. Soneto» de Cristóbal de Mesa (en Las Églogas y Geórgicas de Virgilio y Rimas y el Pompeyo. Tragedia) y el año 2011: «Dos pintores en Belén (El Greco)» de Jorge de Arco (en F. Carratalá, ed., ¡Navidad! ¡Navidad! Antología literaria). El grueso de los poemas corresponde al siglo XX, la sala principal de este museo, comenzando la lectura con tres sonetos debidos a Antonio de Zayas («Domenico Theotocópuli. El inquisidor» de Retratos antiguos, 1902), Francisco Villaespesa («Alma española» de El jardín de las quimeras, s.f.) y Manuel Machado («El caballero de la mano en el pecho» de Apolo. Teatro pictórico, 1911). El retrato modernista tuvo predilección por el soneto, y ello queda reflejado en las composiciones de Fernando López Martín, Álvaro Melián Lafinur y Guillermo Valencia (con sonetos endecasílabos y alejandrinos), frente a poemas editados en las décadas de 1910-1920 más extensos como «El Caballero de la espada. Cuadro del Greco» de Sofía Casanova, en serventesios alejandrinos; «Cuadros del Greco. El caballero de la mano al pecho» [sic] de Francisco Maldonado, en cuartetos de rima cruzada; y «El peregrino del amor», sobre el San Francisco, de Esther López Valencia, en serventesios hexadecasílabos con estribillo. Se selecciona también «El caballero de la mano en el pecho» de Fernando Iglesias Figueroa, conocido en la historia de la poesía española por sus apócrifos becquerianos. Alarcón ordena los poemas por fecha, de tal manera que se repiten autores (como Zayas) o un breve anaglifo, fruto de la colaboración entre los jóvenes García Lorca, Luis Buñuel, Salvador Dalí y José Bello, precede a Unamuno, al que continúa Miguel Hernández. El mencionado anaglifo era una broma que repetían los amigos: «El té / el té, / la gallina / y el Teotocópuli» (p. 199). Persiste el uso del soneto en Hernández, Ángel Valbuena Prat y Ezequiel González Más, y sobrecogen la belleza y la sensibilidad evocadora -volviendo al principio- de «El Greco», de Alberti, del que hay un segundo texto: «(N.Y.)», en el que yo lírico se siente transportado a la ciudad de Toledo al contemplar el lienzo Vista de Toledo, expuesto en el Museo Metropolitano de 
Nueva York: «De pronto encontré Toledo. / No recordaba que aquí / estaba Toledo, una / extraña radiografía / de la ciudad [...] / algo insomne, fascinante, / visto por una sonámbula / pupila del más allá»(p.213). Luis Cernuda dialoga con él mismo desdoblado esta vez en el pintor y el retratado: «Retrato de poeta. Fray H. F. Paravicino, por El Greco", con dedicatoria a Ramón Gaya. Los tiempos y espacios se confunden en esta antología, y el cretense es emoción y nostalgia, exilio y presente. La nómina y la selección poética continúa el decurso de la historia española: León Felipe, Concha Zardoya, Jorge Guillén, José García Nieto, Pablo García Baena, Diego Jesús Jiménez o José Luis Rey, entre los más destacados.

El volumen se cierra con una rica bibliografía en distintas lenguas. Echo en falta un índice de los poemas y poetas incluidos en la antología, que no consta, cuando, paradójicamente, sí hay uno de autores destacados (que van en negrita) correspondientes al capítulo segundo, «El Greco en la poesía hispánica».

En conclusión, este libro supone una destacada y brillante contribución al esclarecimiento de la figura de El Greco en la cultura hispánica. Como estudio es útil tanto para historiadores del arte como de la literatura. Y la antología es un regalo tanto para la vista, como para la sensibilidad y el intelecto.

\section{AUTORES}

\section{MARTA PALENQUE}

Universidad de Sevilla 